\title{
Atypical Presentation of Triple-Negative Breast Cancer
}

\section{Ramon Eduardo Garcia-Cahuich ${ }^{1}$, Felipe Rodríguez-Solis ${ }^{1}$, Nancy E. García-Carrillo ${ }^{2}$, Alondra Yereldi Naranjo-Cruz ${ }^{3}$, Lorena Berenice Hernández-Hoil ${ }^{4}$ and María Valeria Jiménez-Báez ${ }^{5 *}$}

${ }^{1}$ Medical Intern of Social Service, Unit No 16 Cancún, Mexican Institute of Social Security, Mexico

${ }^{2}$ Department of Gynecology, General Hospital Regional No. 17, Mexican Institute of Social Security, Mexico

${ }^{3}$ Department of Oncology, General Hospital Regional No. 17, Mexican Institute of Social Security, Mexico

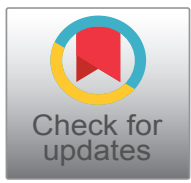

${ }^{4}$ Department of Internal Medicine, General Hospital Regional No. 17, Mexican Institute of Social Security, Mexico

${ }^{5}$ Head of Medical Benefits Services, Coordinator of Institutional Planning and Liaison, Mexican Institute of Social Security, Mexico

*Corresponding author: María Valeria Jiménez Báez, Head of Medical Benefits Services, Coordinator of Institutional Planning and Liaison, Mexican Institute of Social Security, Av. Politécnico Nacional S/n, Cancún, Quintana Roo, Mexico, Tel: 9988742354

\begin{abstract}
Summary
Introduction: Triple-Negative Breast Cancer (BCTN) has been defined as the absence of Estrogenic Receptors (ER), Progesterone Receptors (EP), Epidermal growth factor receptor 2 (HER2), and it conforms 10 to $20 \%$ of all cases of breast cancer.

Case report: A 42-years-old female, debuting with abdominal pain, a 44 pounds of weight loss on the last 2 months and abdominal mass presence. A single complex looking nodule found in the left breast, which underwent a biopsy with results of triple negative breast adenocarcinoma, she had kidney failure, hypoglycemia and neurological impairment concluding in death.
\end{abstract}

Discussion: Triple-Negative Breast Cancer occurs in young women, it has an aggressive development, it characterized by present brain metastasis giving to it an ominous prognostic.

\section{Keywords}

Breast cancer, Triple negative

\section{Abbreviations}

BCTN: Triple-Negative Breast Cancer; BC: Breast Cancer; ER: Estrogenic Receptors; RP: Progesterone Receptors; HER2: Epidermal Growth Factor Receptor 2

\section{Introduction}

Breast cancer ranks first in incidence and leading cause of death among women in the world [1-6]. In one year, 2,261,419 million cases of cancer have been diagnosed, of which breast cancer represents $11.7 \%$ of all types of cancer with 684,996 deaths reported [1]. A patient suffering breast cancer has about 77 years of life expectancy and being diagnosed with an average of years of 52.5-years-old, being the majority diagnosed after 50 -years-old, a $23 \%$ are found in those under 45 -years-old $[5,6]$.

Only $10 \%$ of breast cancer cases have genetic background, being the majority, sporadic (90\%) [5]. The definitive diagnostic is made by biopsy with positive results of malignancy classified by immunohistochemistry (IHC) depending by positivity of Estrogenic Receptors (ER), Progesterone Receptors (PR) and Epidermal growth factor receptor 2 (HER2) $[4,6,7]$. Immunohistochemistry classification is being classified by subtypes: Luminal A, Luminal B, HER2 positive and Triple-negative [7]. In Mexico, the incidence according to the IHC is of hormone receptors $60 \%$, HER-2 positive $20.4 \%$ and triple-negative $23.1 \%$ [8].

The Triple negative Breast Cancer (BCTN) it been defined as the absence of Estrogenic Receptors (ER), Progesterone Receptors (EP), Epidermal growth factor receptor 2 (HER2) [2,4,8-11], and it conforms 10 to $20 \%$ of all cases of breast cancer $[10,12,13]$. It has been made a study by Acta Medica Grupo Angeles, in the Angeles 
Pedregal Hospital in Mexico where it is observed during a period of 2009-2015 of 3,290 samples only $9.6 \%$ of the cases were BCTN cases [14]. Histologically, the most common BCTN is the Invasive Ductal Breast Carcinoma, other unusual BCTN are Apocrine and Adenoid cystic with better prognostic $[7,8]$. The most characteristic presentation includes young patients, under 40-yearsold, are considered to have a poor prognosis due to very rapid distant metastases, and more probability of shortterm recurrence $[2,8,10,13]$.

The molecular profile has shown that Breast Cancer (BC) is a heterogenous disease. The BCTN it's classified base on the genetic expression in 6 molecular subtypes; basal like (BL1 and BL2), Immunomodulator (IM), Mesenchymal (M), Mesenchymal Stem Like (MSL) and luminal androgen receptor subtype (LAR) [7].

The objective of this project is to present the case of a patient with an aggressive triple-negative breast cancer, with a second primary tumor, to describe its clinical evolution and to present a scientific review of the literature.

\section{Case Report}

A 42-years-old female patient diagnosed with Diabetes Mellitus Type 2 on 2018, originally from Campeche, Mexico, currently living in Cancun Quintana Roo since 2000, without hereditary family history, no previous mammograms, current illness begins when she comes to emergency room starting with sudden abdominal pain with thoracic and lumbar irradiation, 44 pounds of weight loss during the last 2 months, accompanied by intolerance to the oral route. In the exploration the patient presents an ECOG 2, Periumbilical ecchymosis, stone-like abdominal tumor of 4 inches, The Abdominal Ultrasound (USG) reported abdominal fluid collection, gallbladder with bile sludge, right pleural effusion and bilateral pyelocaliceal ectasia.
Multidisciplinary studies start with her admission on Internal medicine with suspected diagnosis of Gastric cancer, In Table 1, it shows the analytical evolution of the laboratories. Reporting anemic syndrome, acute kidney injury AKIIN 3 and Hyperkalemia. Oncological Gynecology report suspicion of primary carcinoma. For a $1.5 \times 1.4$-inch breast tumor was found in the physical examination in the left breast, and inflammatory lymphadenopathy. A mammogram and biopsy were requested, assessed by hematology for pancytopenia and bone involvement in the rib cage with suspected clinical diagnosis of neoplasia, in particular multiple myeloma, she requested complementary studies.

On 12/01/2021 the Abdominal-Pelvic Tomography results were obtained (Figure 1 ) it reported a probable bone tumor of the second left costal arch with metastases to the axial and appendicular bone. A thoracoscopic biopsy of that mass of the second costal arch was done, reporting tiny multiple tissues fragments that together measure $0.6 \times 0.7 \times 0.07$ inches, light brown, soft consistency, mucous appearance. The histological report shown neoplasm compatible with Giant cellrich tumor. The results of Mammogram (Figure 2a) and Breast USG report heterogeneous poorly circumscribed nodule, elastographic hardness pattern, with peripheral vascular activity and afferent flow (Figure $2 b$ ) measure $25 \times 31 \times 22 \mathrm{~mm}$ located on breast upper and outer quadrant, being classified as BIRADS $4 \mathrm{~b}$ and a biopsy is requested.

10 days after hospitalization the patient starts to present generalized jaundice, pancytopenia, cholestatic pattern and acute kidney failure, subsequently present hypotension, hypoglycemia, neurological impairment, state of shock, it gets certified as death by acute kidney failure.

The post-mortem results of histopathology and immunohistochemical studies on the left breast

Table 1: Biochemical parameters during hospitalization.

\begin{tabular}{|c|c|c|c|c|c|c|}
\hline Labs & $30 / 12 / 2020$ & $7 / 01 / 2021$ & $12 / 01 / 2021$ & $18 / 01 / 2021$ & $19 / 01 / 2021$ & $21 / 01 / 2021$ \\
\hline Glucose & $132 \mathrm{mg} / \mathrm{dL}$ & - & $126 \mathrm{mg} / \mathrm{dL}$ & $95 \mathrm{mg} / \mathrm{dL}$ & - & $69 \mathrm{mg} / \mathrm{dL}$ \\
\hline Urea & $52.3 \mathrm{mg} / \mathrm{dL}$ & - & $95 \mathrm{mg} / \mathrm{dL}$ & $108 \mathrm{mg} / \mathrm{dL}$ & - & $136 \mathrm{mg} / \mathrm{dL}$ \\
\hline Creatinine & $3.6 \mathrm{mg} / \mathrm{dL}$ & - & $2.44 \mathrm{mg} / \mathrm{dL}$ & $2.34 \mathrm{mg} / \mathrm{dL}$ & - & $2.55 \mathrm{mg} / \mathrm{dL}$ \\
\hline GFR CKD-EP1 & $14.8 \mathrm{~mm} / \mathrm{min}$ & - & $23.6 \mathrm{~mm} / \mathrm{min}$ & $24.8 \mathrm{~mm} / \mathrm{min}$ & - & $22.4 \mathrm{~mm} / \mathrm{min}$ \\
\hline Hemoglobin & $10.6 \mathrm{~g} / \mathrm{dL}$ & - & $8.1 \mathrm{~g} / \mathrm{dL}$ & $8.8 \mathrm{~g} / \mathrm{dL}$ & - & $5.5 \mathrm{~g} / \mathrm{dL}$ \\
\hline Hematocrit & $31 \%$ & - & $23.7 \%$ & - & - & - \\
\hline Platelets & $96 \mu \mathrm{L}$ & - & $68 \mu \mathrm{L}$ & $52 \mu \mathrm{L}$ & - & $4 \mu \mathrm{L}$ \\
\hline Leukocytes & $8.6 \mu \mathrm{L}$ & - & $4.3 \mu \mathrm{L}$ & $3.7 \mu \mathrm{L}$ & - & $2.2 \mu \mathrm{L}$ \\
\hline Sodium & - & 143 mEq/L & $145 \mathrm{mEq} / \mathrm{L}$ & $147 \mathrm{mEq} / \mathrm{L}$ & - & $162 \mathrm{mEq} / \mathrm{L}$ \\
\hline Calcium & - & $13.3 \mathrm{mg} / \mathrm{dL}$ & $13.5 \mathrm{mg} / \mathrm{dL}$ & $13.3 \mathrm{mg} / \mathrm{dL}$ & - & $13.19 \mathrm{mg} / \mathrm{dL}$ \\
\hline GDT & $28.2 \mathrm{UI} / \mathrm{L}$ & - & $41 \mathrm{UI} / \mathrm{L}$ & - & - & $90.3 \mathrm{UI} / \mathrm{L}$ \\
\hline GPT & $29.7 \mathrm{UI} / \mathrm{L}$ & - & 49 UI/L & - & - & 54.4 UI/L \\
\hline Billirubine & $0.66 \mathrm{mg} / \mathrm{dL}$ & - & - & - & $7.82 \mathrm{mg} / \mathrm{dL}$ & $13.6 \mathrm{mg} / \mathrm{dL}$ \\
\hline
\end{tabular}




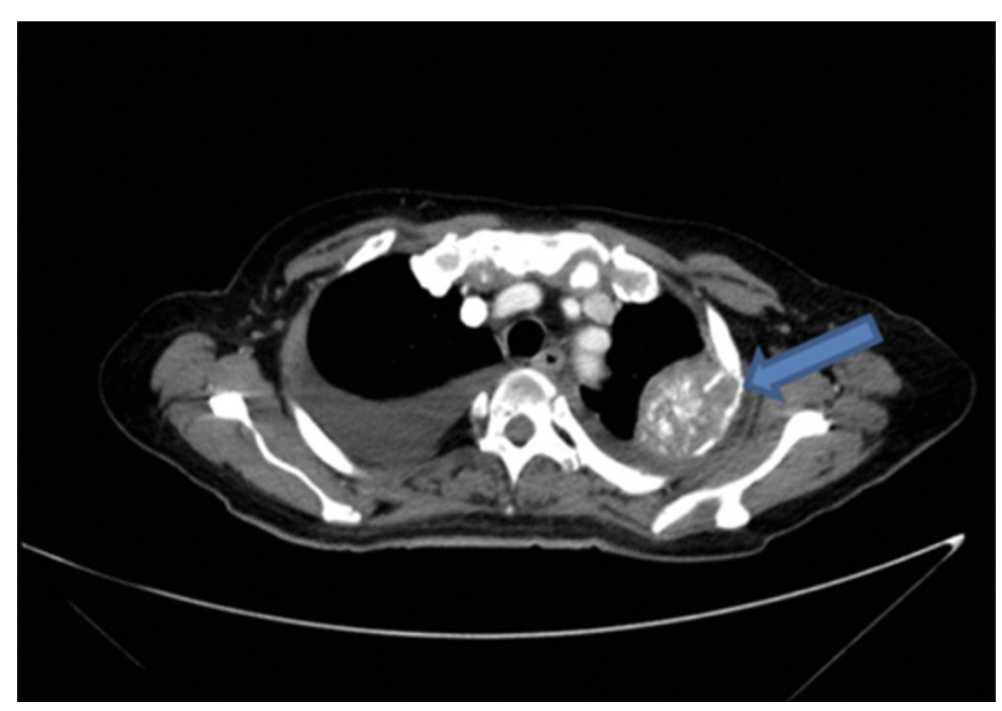

Figure 1: Computed Tomography: Computed tomography thoracoabdomino-pelvic A tumor is observed in the $2^{\text {nd }}$ costal arch, as well as lysis of the left rib.

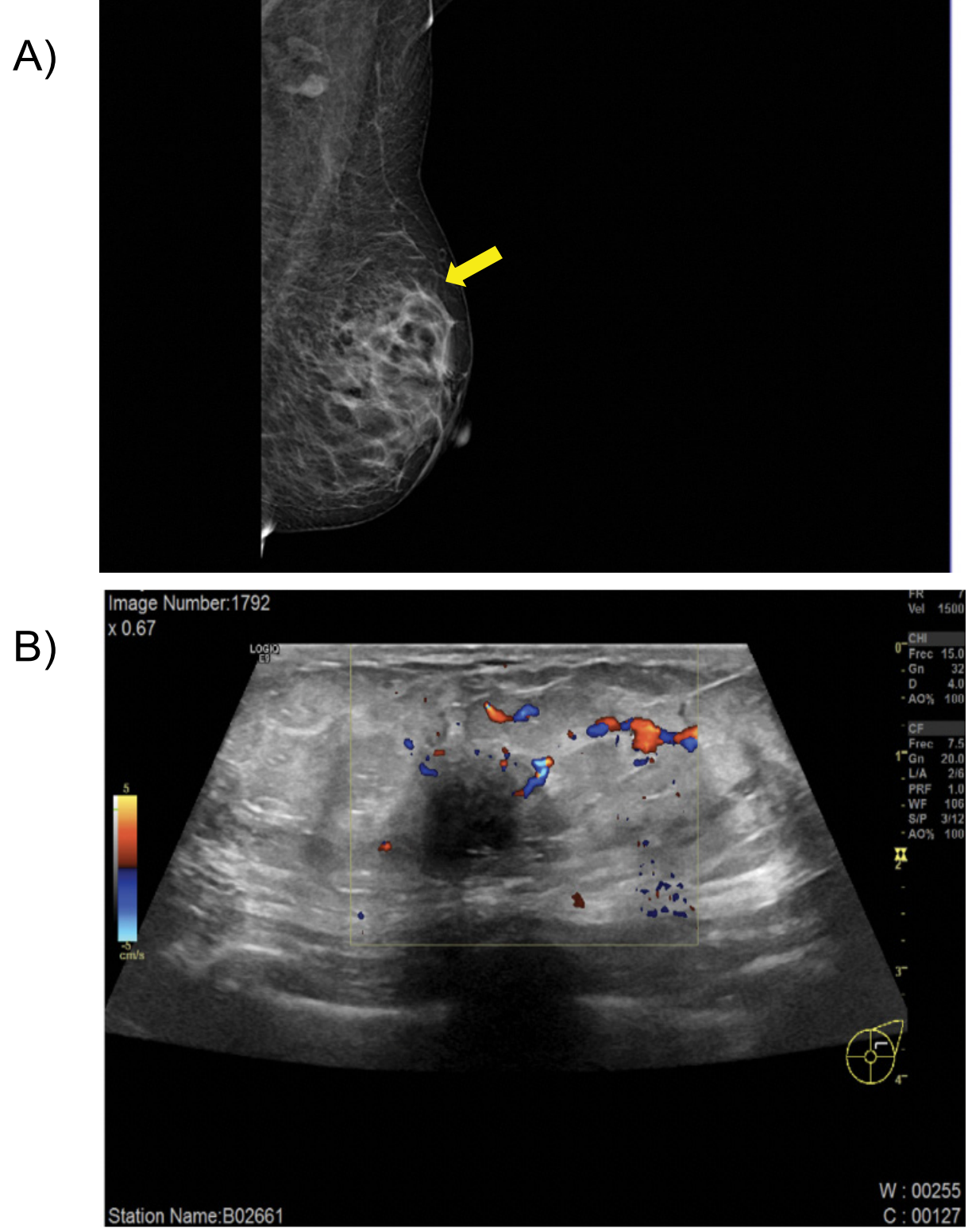

Figure 2: (a) Mammogram: Left breast mammogram, breast tissue is observed with fibroglandular component poorly dispersed, asymmetric, BIRADS 4b; (b) Doppler Ultrasound: Left breast Doppler ultrasound, upper left quadrant peripheric vascular activity and afferent flow is observed. 
tumor reports Invasive Triple-negative Breast Cancer Adenocarcinoma.

\section{Methodology Review}

It has been made a literature review through a scientific database, The established objectives for the evidence search and interpretation were:

- Identify systematic review and metanalyses that distinguish the BCTN diagnosis, treatment and prevention.

- Recognize relevant information to analyze BCTN cases.

\section{Research strategy}

The research strategy has been focused on interesting keywords such as: "Triple-Negative Breast Cancer". The search term used includes the title of recognized medical subject (MESH): ("Triple Negative Breast Neoplasms" [Mesh]). It has been realized in the following database: Pubmed, Journal of the American
Medical Association (JAMA), New England Journal of Medicine (NEJM), LILACS, Elsevier. The maximum date of publication of the articles was ranged from 5 years ago to the present (2016-2021).

\section{Criteria}

The inclusion criteria were full text scientific articles Meta-analyzes, Systematic Review about TripleNegative Breast Cancer, we take studies published in any language, the exclude criteria were articles published before 2016 .

\section{Research results}

From the research of different database, were found 6'527 articles, resulting on 158 articles after the 5-years exclusion, 64 meta-analyzes and systematic review articles were obtained, 26 articles were obtained after title and abstract review, and finally 15 articles were obtained after full reading, including who will talk about BCTN diagnosis, treatment or prevention (Figure 3).

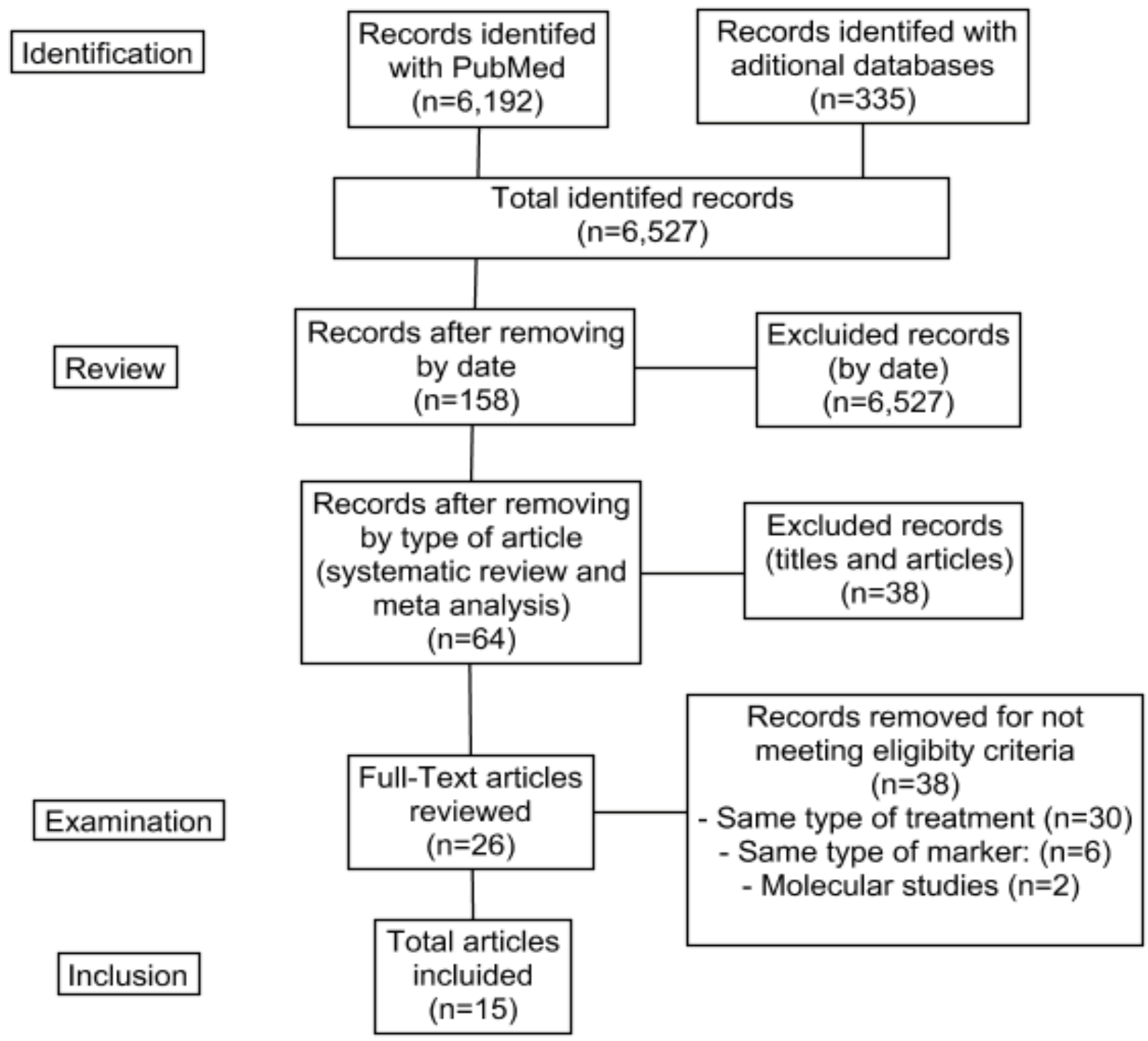

Figure 3: Search diagram: Methodology articles review like PRISMA. 


\section{Discussion}

Triple-Negative Breast Cancer (BCTN) has been defined as the absence of Estrogenic Receptors (ER), Progesterone Receptors (EP), Epidermal growth factor receptor 2 (HER2) [2,4,8-11] and it conforms 10 to $20 \%$ of all cases of breast cancer $[10,12,13]$. On this occasion the patient starts suffering from acute abdominal pain and is being detected with an unknown origin abdominal mass.

The most notable aspect about this case report is the initial aggressiveness and the atypical form with which the patient debuted, according to what is reported in the literature $[3,4,8,11,12,14,15]$. The most common initial clinical picture is the single breast nodule on TNBC, even less often (under 0.5\%) [5]. The initial picture of breast cancer could be a single giant-cell tumor $[4,16]$. The atypical forms founded in the literature are the case of TNBC with dermatomyositis and other one with hypercortisolism by an Adrenocorticotropic Hormone (ACTH) dependent tumor [17].

Initially our patient presents a status called visceral crisis, that is defined as a severe organic death, evaluated by sign and symptoms, laboratory studies and fast progression of disease [18]. The Visceral Crisis is not just visceral metastases presence, but it involves significant organ involvement leading to a clinical indication for more rapidly effective therapy. An increase in total bilirubin from $0.66 \mathrm{mg} / \mathrm{dl}$ to $7.82 \mathrm{mg} / \mathrm{dl}$ was observed in the patient in only 20 days, meeting the $A B C 5$ consensus definition [18]. As for visceral crisis, it is defined like a total bilirubin increase from 1.5 than normal values.

There are breast cancer cases with heterogenous clinical sign, a screening method to detect the initial clinical picture before present advanced stages, the main screening method used around the world is the mammogram which with it has to been realized to every upper 40-years-old women [19]. The main advantage of mammogram is the only screening method that could decrease mortality until $21 \%$ and it has a sensibility of $77-95 \%$ and specificity of $94-97 \%$ depending of breast density [19]. The imaging finding in this patient was the poorly circumscribed nodule, that could be the initial finding until a $82.2 \%$ of all cases [13].

However, is referred that until a $18.2 \%$ of all female patient does not present mammographic manifestations [13], hindering to their diagnose, especially in dense breast where the mammogram effectiveness can be seen altered (1.9 to 4.2 additional cancers for every 1000 women). For that reason, The Breast USG can be used as a diagnostic complement in this kind of cases, In accordance with meta-analyses [20]. The TNBC ultrasonographic characteristics are: Irregular form, no angular or spiculate margin, rear acoustic enhancement and abrupt interface. By having similar benign breast tumor characteristics, it can be differentiated with microlobular edges, this type of edges has an upper appearance rate on TNBC [20].

When a suspicious malignancy tumor is founded in the mammogram, immediate biopsy is indicated, the diagnostic golden standard is the cutting needle biopsy with a sensibility of $97.1 \%$ and specialty of $100 \%$ $[21,22]$. The IHC has been used to guide and classify breast tumor in addition to providing a prognosis so they must be performed to all patient with confirmatory diagnosis of Breast Cancer [22]. The time between the detection of a clinical tumor and the performance of the recommended diagnostic tests is essential to establish treatment.

The main TNBC tumors are bigger, higher grade and grow quickly. They are cancers that occur more frequently between mammographic screening and are clinically detectable at the time of diagnosis. The presence of lymph node metastases at the time of diagnosis is conflictive. Some authors suggest a higher metastases prevalence on lymph nodes, The TNBC doesn't correlate with the size of the mentioned tumor, $55 \%$ of women with a 0.4 inches or smaller tumors in their study has at least a single lymph node positive, beside that, The Caroline Breast Cancer Story does not report any association with positive axillary lymphatic nodule and basal-like subtype [9].

It's more probably that Metastatic TNBC affect to organs such as the brain by up to $32 \%$ compared to $15 \%$ of receptor-positive tumor [23]. They are less likely to affect bones (6.4\%) in contrast to their luminal counterpart (9.4\%), especially on patients under 40-years-old [24]. The TNBC has a higher proportion of patients that will experience distance recurrence (27.4\%) compared to local recurrence (12\%) [25]. In the patient case, the costal arch tumor corresponded to another primary tumor, but not metastasis itself.

The differential diagnosis was included multiple myeloma, due to hypercalcemia, kidney insufficiency and anaemia, bone pain and weight loss, for the differential approach, it is proposed that serum protein electrophoresis can detect the monoclonal protein M-spike, characteristic of these patients, in up to $82 \%$. The addition of immunofixation increases sensitivity by up to $93 \%$ [26]. This study is available in hospitals of the public health sector, so the access to these tests has been one of the policies of change in our system, despite this, the challenge facing the clinician is the readiness of the result in a short time.

According to actual guidelines of Metastatic TNBC [27] recommend to realize genetic tests of BRCA and PD-L1 gene mutation detection, patients with altered studies are candidates for targeted treatments that improve survival. In BRCA alterations targeted therapy with Talazoparib or Olaparib, both PARP inhibitors, should be initiated. The PD-L1 alterations, treatment 
should include atezolizumab or pembrolizumab, a novel immunotherapy that, in conjunction with neoadjuvant chemotherapy, significantly improves pathologic complete response (pCR) rates [28,29]. In terms of Chemotherapy or ignorance of the status of these genes, treatment can be initiated depending on previous exposure to anthracyclines or taxanes, our case has not received previous chemotherapy, so the first line treatments are carboplatin and anthracyclines or taxanes. However, Ki67 high levels shown anthracyclines resistance, its measurement should be included in the study protocol, $\mathrm{Ki} 67$ is also a predictor of poor prognosis [30].

On advance TNBC patients, the best proven regimen is the combined use of bevacizumab, carboplatin and paclitaxel [31]. It is worth to noting that platinum regimen has a greater impact on the life quality and survival in contrast to patients who do not contain platinum in their treatment $[29,32]$. The new treatment options for advance TNBC patients are the polymerase inhibitors (PARPi) such as labarib, rucaparib and niraparib in conjunction with chemotherapy especially for patients with previous response to platinum and BRCA1/2 mutation [33,34].

The early detection by mammogram is recommended to be performed annually between $40-70$ years-old for early diagnosis. In Mexico, according to the "Norma Oficial Mexicana 041" [35,36] of Breast Cancer refer about breast cancer early detection, it recommends that screening studies should be started at age 40-years-old or older. In this situation our patient did not have breast cancer screening or an early detection mammogram in spite of her history of high Body Mass Index (BMI). However, having no history of breast cancer in the family is not an impediment to suspected breast cancer, as only $37.93 \%$ have a history of breast cancer [37], and up to $90 \%$ are sporadic [5].

In Mexico, 1.5 million mammograms are performed annually on women aged 40-69 years-old [38] and about $\$ 2,752,321,069$ pesos are spent on breast cancer prevention programs. In other countries, such as the United States, the estimated expenditure is US\$16.5 billion, being the breast cancer the highest cost in that country [39]. Despite the significant expenditure on prevention, there are other factors that can occur due to the lack of timely diagnosis of breast cancer.

The population factor is a determinant that is influenced by the patient's culture regarding health and prevention habits, since, despite the existence of programs, dissemination and invitation to perform breast cancer screening for women, the population does not present specific actions to adhere to the protocols for breast cancer screening. Another factor that influences screening is the unawareness of health personnel in relation to screening, reaching scores of 64 when surveys are applied to them regarding breast cancer [40]. It is important to training and raising awareness on those subjects.

Mexico is one of the countries in Latin America with the highest investment in preventive health, however, when compared to developed countries, the lag is notable in terms of investment and culture of prevention among the population.

In terms of prevention, 25-hydro-vitamin D screening is recommended, as low levels of this test are associated with the occurrence of TNBC [41]. Another promising measure, although more studies are needed, is the use of beta-blockers, as it has been documented to improve progression, recurrence and survival of the disease by inhibiting metastasis, angiogenesis and tumor growth [42]. Breastfeeding is an action that should be promoted from the primary care, being a simple and low-cost measure that can reduce the probability of developing TNBC by up to $21 \%$ [43]. Although it is controversial whether obesity influences disease-free survival and overall survival, a normal BMI is recommended [44,45].

According to the published literature, our patient's survival could have been as high as 49 to $68 \%$ [3]. An example of this situation is a study of 222 women diagnosed with breast cancer, where $18 \%$ were triple negative, with a 5 -year survival rate of $96 \%$ in early stages, and only 2 women were diagnosed in late stages, with no 5-year survival [8]. In a Systematic Review, $6 \%$ had metastatic disease, with a 5 -year survival rate of only $26.4 \%$ [39]. Here lies the importance of its detection, since mortality is related to late diagnosis and an advancement of the tumor stage, in addition to being able to apply preventive measures already mentioned that can improve the overall survival of patients.

\section{Conclusion}

The Triple-Negative Breast Cancer is the subtype with the most aggressive clinical course and is associated with an ominous prognosis, with a short progressionfree survival and poor Global Survival (GS). The median GS on metastatic TNBC is approximately 12 to 18 months with chemotherapy. It is proposed to reinforce preventive measures against breast cancer for timely detection such as the case presented for this patient, as well as to train health professionals and increase the number of detections, since early diagnosis leads to timely intervention. It is important to apply screening measures to detect in time atypical cases before they present advanced stages and have a negative impact on overall survival. Likewise, the diagnosis of breast cancer should be included in the differential of oncologicaloriented diseases, especially when there are clinical conditions that are indicative of breast cancer.

\section{Conflict of Interest Statement}

The authors declare no conflict of interest in this review. 


\section{Financing Sources}

The authors did not receive funding for this case presentation.

\section{References}

1. Ferlay J, Ervik M, Lam F, Colombet M, Mery L, et al. (2020) Global Cancer Observatory: Cancer Today. Lyon, France: International Agency for Research on Cancer.

2. Gui X, Li H, Song G, Shao B, Jiang H (2018) Long term use of bevacizumab in the treatment of triple negative breast cancer with giant tumor in chest wall. Medicine 97: e13410.

3. Romeira D, Cardoso D, Miranda H, Martins A (2016) Adenoid cystic carcinoma: triple negative breast cancer with good prognosis. BMJ Case Rep 2016: bcr2015213704.

4. Chielli G, Borges J, Martins G, Lacerda T, Lombardi W, et al. (2021) Câncer de Mama Multifocal: Relato de Caso. Revista Brasileira de Cancerologia 2020: 66.

5. Consenso Mexicano sobre Diagnóstico y Tratamiento de Cáncer Mamario. Octava Revisión. GAMO 2019 18: 6-36.

6. John E, James O, James H, Michael B, Joel E (2020) Abeloff's Clinical Oncology. (6 $6^{\text {th }}$ edn), USA, Elsevier.

7. Khosravi-Shahi $P$, Cabezón-Gutiérrez L, Aparicio Salcedo M (2019) State of art of advanced triple negative breast cancer. Breast J 25: 967-970.

8. Quirós J, Espinoza K (2017) Supervivencia a 5 años de pacientes con cáncer de mama triple negativo. Med Leg Costa Rica 34: 59-72.

9. Tan T, Dent R (2021) Triple-Negative Breast Cancer: Clinical Features. In: Tant T, Triple-Negative Breast Cancer. $1^{\text {st }}$ edn, Singapore: Springer, Cham, 2018: 22-32.

10. Kubeček O, Soukup T, Paulík A, Kopecký J (2016) Dermatomyositis with anti-TIF-1Y antibodies as a presenting symptom of underlying triple-negative breast cancer: $A$ case report. BMC Cancer 16 .

11. Ruiz J, Recuero M, Cárdenas J, Cifuentes I, Álvarez J, et al. (2021) Low-grade triple-negative breast carcinomas. A report of 2 cases and an update of current concepts. Revista Española de Patología.

12. Sarachi I, Toledo A (2017) Tumor de mama triple negativo diagnosticado como una asimetría en desarrollo. Revista Argentina de Radiología 81: 304-306.

13. Casimo C, Arra M, Gentila L, Martinez F, Stigliano J, et al. (2018) Triple Negative Breast Cancer imaging characteristics. Rev Argent Mastología 37: 95-109.

14. Wan C, Chen L, Chen H, Yang S, Hu J (2020) Triplenegative breast cancer with calcified metastases of hepatic, portal vein and inferior vena cava: Report of a case and review of the literature. Journal of the Formosan Medical Association 119: 1431-1434.

15. Dey N, Krie A, Klein J, Williams K, McMillan A, et al. (2017) Down's Syndrome and Triple Negative Breast Cancer: A Rare Occurrence of Distinctive Clinical Relationship. Int $J$ Mol Sci 18: 1218

16. Elias AD, Wang WS, Hardesty L (2016) A 55-Year-Old Woman with New Triple-Negative Breast Mass, Less Than $2 \mathrm{~cm}$ on Both Mammogram and Ultrasound. Oncology (Williston Park) 258-262.

17. Hodorowicz-Zaniewska D, Brzuszkiewicz K, Szpor J (2019) Triple negative breast cancer with ACTH-dependent Cushing's syndrome - case report. Polish Journal of Surgery 91: 45-47.
18. Thomssen $C$, Lüftner $D$, Untch $M$, Haidinger R, Würstlein $\mathrm{R}$, et al. (2020) International Consensus Conference for Advanced Breast Cancer, Lisbon 2019: ABC5 Consensus - Assessment by a German Group of Experts. Breast Care 15: 82-95.

19. Ettinger D, Handorf C, Agulnik M, Bowles D, Cates J, et al. (2014) Occult Primary, Version 3.2014. J Natl Compr Canc Netw 12: 969-974.

20. Tian L, Wang L, Qin Y, Cai J (2020) Systematic Review and Meta-analysis of the Malignant Ultrasound Features of Triple-NegativeBreast Cancer. Journal of Ultrasound in Medicine 39: 2013-2025.

21. Hashirekha C, Rahul R, Ravikiran H, Sreeramulu P, Krishna $P$ (2021) Fine needle aspiration cytology versus trucut biopsy in the diagnosis of breast cancer: a comparative study [Internet]. International Surgery Journal.

22. Consuelo H-Á, Catalina R-A, de Iturbide Cecili O (2017) Cáncer de mama triple negativo: Frecuencia y características en el Hospital Ángeles Pedregal. Acta Méd Grupo Ángeles 15: 269-274.

23. Kuksis M, Gao Y, Tran W, Hoey C, Kiss A, et al. (2020) The incidence of brain metastases among patients with metastatic breast cancer: a systematic review and metaanalysis. Neuro-Oncology 23: 894-904.

24. Shi D, Bai J, Chen Y, Wang X, Zhang Y, et al. (2020) Predicting the Incidence and Prognosis of Bone Metastatic Breast Cancer: A SEER-Based Observational Study. BioMed Research International 2020: 1-9.

25. Wu X, Baig A, Kasymjanova G, Kafi K, Holcroft C, et al. (2016) Pattern of Local Recurrence and Distant Metastasis in Breast Cancer By Molecular Subtype. Cureus 8: 924.

26. Jame A. James L (2019) The Bethesda Handbook of Clinical Oncology. ( $5^{\text {th }}$ edn), Philadelphia, USA, Wolters Kluwer.

27. Loibl S, Poortmans P, Morrow M, Denkert C, Curigliano G (2021) Breast cancer. The Lancet 397: 1750-1769.

28. Tarantino P, Gandini S, Trapani D, Criscitiello C, Curigliano $G$ (2021) Immunotherapy addition to neoadjuvant chemotherapy for early triple negative breast cancer: A systematic review and meta-analysis of randomized clinical trials. Critical Reviews in Oncology/Hematology 159: 103223.

29. Miyashita H, Satoi S, Cruz C, Malamud S (2020) Neoadjuvant therapy for triple-negative breast cancer: Insights from a network meta-analysis. The Breast Journal 26: 1717-1728.

30. Gui Y, Xu S, Yang X, Gu L, Zhang Z, et al. (2016) A metaanalysis of biomarkers for the prognosis of triple-negative breast cancer patients. Biomarkers in Medicine 10: 771 790.

31. Tian Q, Du P, Li S, Bai Z, Yang Y, et al. (2017) Effect of antitumor treatments on triple-negative breast cancer patients. Medicine 96: e8389.

32. Kaya V, Yildirim M, Yazici G, Gunduz S, Bozcuk H, et al. (2018) Effectiveness of Platinum-Based Treatment for Triple Negative Metastatic Breast Cancer: a Meta-Analysis. Asian Pac J Cancer Prev 19: 1169-1173.

33. Chen Z, Wang X, Li X, Zhou Y, Chen K (2021) Deep exploration of PARP inhibitors in breast cancer: Monotherapy and combination therapy. J Int Med Res 49: 030006052199101.

34. Diana A, Franzese E, Centonze S, Carlino F, Della Corte 
C, et al. (2018) Triple-Negative Breast Cancers: Systematic Review of the Literature on Molecular and Clinical Features with a Focus on Treatment with Innovative Drugs. Current Oncology Reports 20.

35. Prevención, Tamizaje y Referencia Oportuna de Casos sospechosos de Cáncer de Mamaen Primer Nivelde Atención. Guíade Evidencia y Recomendaciones: Guíade Práctica Clínica, México: CENETEC.

36. Norma Oficial Mexicana NOM-013-SSA2-1994 (2003) Prevención, Diagnóstico, Tratamiento, Control y Vigilancia Epidemiológica del Cáncer de Mama, México: Diario Oficial de la Federación.

37. Tapia MJ, Adrian PF, Marco LT, Isabel GF, Vincent G, et al. (2019) Características clínico-patológicas del cáncer de mama triple negativo. Revisión de cinco años. Revista Venezolana de Oncología 31.

38. Navarrete-Valero C, Navarrete-Vázquez C (2018) Mortalidad por cáncer mamario, prostático y cervicouterino, años perdidos y costos de los programas. México, 2013 a 2016. Gaceta de Mexico 154.

39. Parisi M, Pelletier C, Cherepanov D, Broder M (2018) Outcomes research examining treatments, quality of life and costs in HER2-negative and triple-negative metastatic breast cancer: a systematic literature review. J Comp Eff Res 7: 67-83.
40. Chávarri GY, Villarreal $C$, Liedke $P$, Knaul $F$, Mohar $A$, et al. (2012) Breast cancer in Mexico: A growing challenge to health and the health system. Lancet Oncol 13: 335-e343.

41. Tommie J, Pinney S, Nommsen-Rivers L (2018) Serum Vitamin D Status and Breast Cancer Risk by Receptor Status: A Systematic Review. Nutr Cancer 70: 804-820.

42. Spini A, Roberto G, Gini R, Bartolini C, Bazzani L, et al. (2019) Evidence of $\beta$-blockers drug repurposing for the treatment of triple negative breast cancer: A systematic review. Neoplasma 66: 963-970.

43. Lambertini M, Santoro L, Del Mastro L, Nguyen B, Livraghi L, et al. (2016) Reproductive behaviors and risk of developing breast cancer according to tumor subtype: A systematic review and meta-analysis of epidemiological studies. Cancer Treat Rev 49: 65-76.

44. Mei L, He L, Song Y, Lv Y, Zhang L, et al. (2018) Association between obesity with disease-free survival and overall survival in triple-negative breast cancer. Medicine 97: e0719.

45. Pinheiro R, Monteiro G (2019) Influência do Índice de Massa Corporal na Sobrevida de Mulheres com Diferentes Subtipos de Câncer de Mama: uma Revisão Integrativa. Revista Brasileira de Cancerologia 65. 